\title{
Unusual impalement injury in a Jehovah's Witness
}

\author{
M. Lanthaler, MD, M. Freund, MD, R. Margreiter, MD, PhD, and H. Nehoda, MD, PhD, Innsbruck, Austria
}

I mpalement injuries are caused by elongated objects, such as metal or wooden stakes, that penetrate and remain in the human body. We here describe the case of a 44-year-old male Jehovah's Witness who survived a most unusual triple abdominothoracic impalement injury.

\section{Clinical Summary}

A 44-year-old man sustained a triple impalement injury after a backward fall of $3 \mathrm{~m}$ onto metal reinforcement rods. Two of these iron rods entered the patient's left side just above the gluteus muscle. The third iron hit the patient somewhat higher up.

On arrival at the emergency department of our hospital, the patient's pulse rate was 100 beats/min, and his blood pressure was 130/85 mm Hg. A computed tomographic scan of the thorax and abdomen showed the 3 iron rods: 2 had penetrated the gluteal region and entered the left side of the chest, with a massive fluid collection in the thoracic cavity (Figure 1). The third rod, having penetrated the lumbal region, seemed to pass through the 12 th vertebral body and the spinal cord and further into the right thoracic cavity. Hematothorax was also visible on the right side. Three chest tubes were inserted, 2 into the left thoracic cavity and 1 into the right side of the chest. Because the tubes drained $1.5 \mathrm{~L}$ of blood from the left thoracic cavity, the patient was immediately taken to the operating room. At that time, his hemoglobin level was $5.5 \mathrm{~g} / \mathrm{dL}$, but no blood was given in accordance with the patient's wish.

A left posterolateral thoracotomy was performed. About 750 $\mathrm{mL}$ of blood was autotransfused from this site. Two iron rods had passed close to the spine into the posterior mediastinum. One rod was located between the aorta and esophagus without damaging these structures (Figure 2). The other one entered the left thoracic cavity through a $3-\mathrm{cm}$ hole in the diaphragm.

All 3 iron rods were removed: the 2 from the left thoracic cavity under direct vision and that from the right thorax blindly. There was some oozing from the diaphragm and the posterior mediastinum that was easily controlled by means of electrocautery.

A second chest tube had to be placed to treat a recurrent hematothorax on the right side. After draining $1 \mathrm{~L}$ blood, bleeding stopped spontaneously.

From the Department of General and Transplant Surgery, Innsbruck Medical University, Innsbruck, Austria.

Received for publication Aug 24, 2004; accepted for publication Sept 27, 2004.

Address for reprints: Hermann Nehoda, MD, PhD, Department of General and Transplant Surgery, Innsbruck Medical University, Anichstrasse 35, 6020 Innsbruck, Austria (E-mail: hermann.nehoda@uibk.ac.at).

J Thorac Cardiovasc Surg 2005;129:1179-80

$0022-5223 / \$ 30.00$

Copyright $\odot 2005$ by The American Association for Thoracic Surgery

doi:10.1016/j.jtcvs.2004.09.022

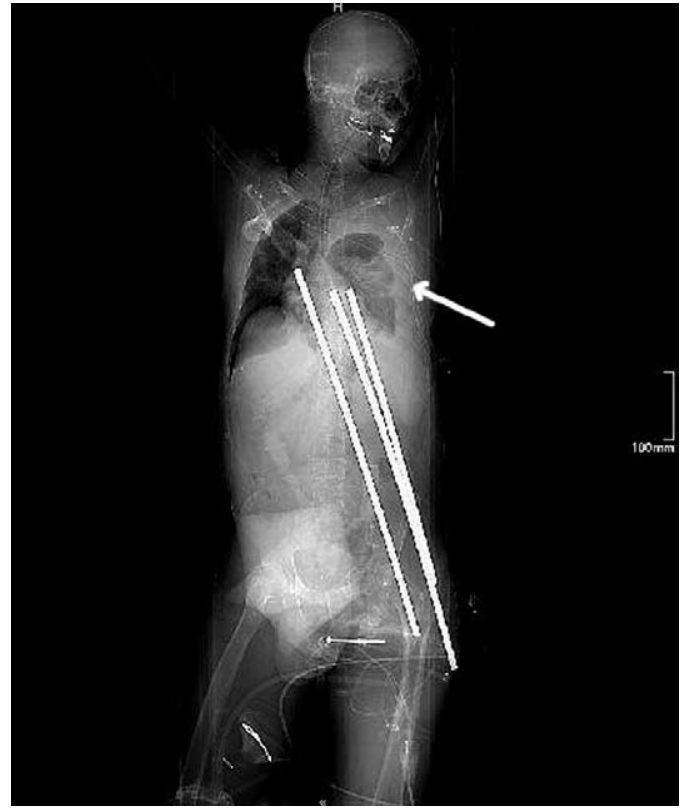

Figure 1. Arrow indicating the hematopneumothorax on the left side.

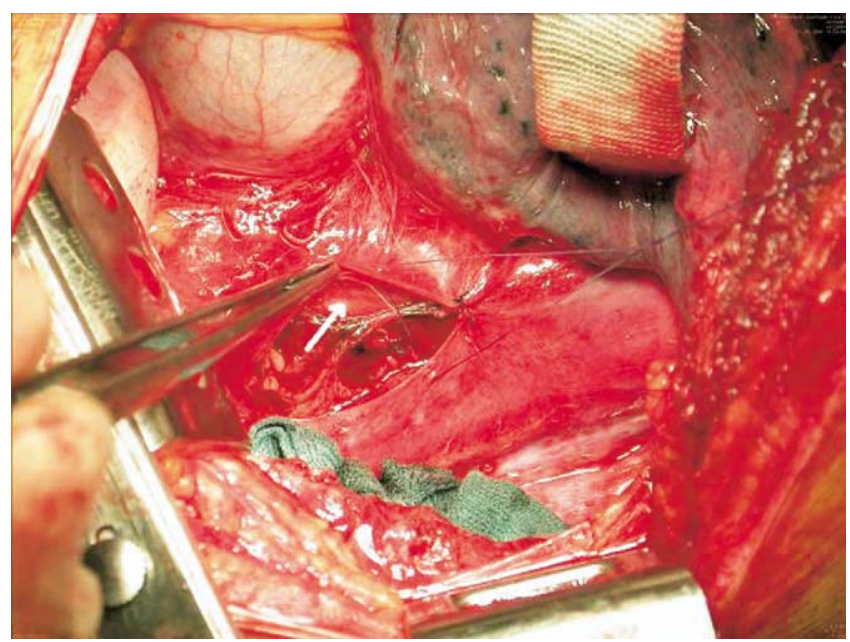

Figure 2. Arrow indicating the uninjured esophagus.

At the intensive care unit, no blood was given, not even on postoperative day 5, when the hemoglobin level reached its lowest value of $3.4 \mathrm{~g} / \mathrm{dL}$ because the patient still refused any blood or blood products. Crystalloid solutions and Ringer lactate were 
given instead. Various factors had to be given to normalize clotting, and the patient also received 10,000 IE erypo (JANSSENCILAG Pharma, Vienna, Austria) daily.

Unfortunately, direct damage of the spinal cord at the level of the 10th thoracic vertebra resulted in complete paraplegia. The patient was extubated on postoperative day 3 and transferred to his home town on day 7 .

\section{Discussion}

Impalement injuries usually occur at construction sites or in motor vehicle crashes or are caused by falling objects. It is crucial to leave the impaling object in situ and remove it under controlled conditions in the hospital. Careful extraction with minimal movement of the impaling object prevents further tissue damage and blood loss. Therefore most authors advise removal under direct vision. ${ }^{1-3}$

In our case a computed tomographic scan revealed a bilateral hematothorax. Chest tubes were inserted to drain both sides, and 1.5 L of blood was removed from the left side within a few minutes. The patient was immediately taken to the operating room with the aim of controlling bleeding and removing the iron rods from the left thoracic cavity under direct vision. The situation was rendered even more dramatic because the patient had refused to receive blood under any circumstances. The rapid loss of more than $40 \%$ of blood volume is usually life-threatening. ${ }^{4}$ For acutely anemic patients, the American Society of Anesthesiologists Task Force on Blood Component Therapy has advised that transfusion is almost always indicated when hemoglobin concentration decreases to less than $6 \mathrm{~g} / \mathrm{dL}^{5}$

Our patient, however, survived a much lower concentration without organ damage apart from paraplegia caused by one of the impaling rods. His survival is certainly not a common clinical experience.

The lesson we learned from this case is that an otherwise healthy subject can tolerate the loss of more blood than is commonly believed.

Rapid assessment of the injury with careful hemostasis after removal of the impaling objects under direct vision together with appropriate fluid replacement was able to save a patient with an extremely unusual and severe impalement injury.

\section{References}

1. Hyde MR, Schmidt CA, Jacobson JG, Vyhmeister EE, Laughlin LL. Impalement injuries to the thorax as a result of motor vehicle accidents. Ann Thorac Surg. 1987;43:189-90.

2. Shimokawa S, Shiota K, Ogata S, Toyohira H, Moriyama Y, Taira A. Impalement injury of the thorax: report of a case. Surg Today. 1994; 24:926-8.

3. Horowitz MD, Ochsner JL. Impalement injuries. Ann Thorac Surg. 1987;44:676-7.

4. American College of Surgeons. Advanced trauma life support course manual. Chicago (IL): American College of Surgeons; 1997. p. 103-12.

5. American Society of Anesthesiologists Task Force. Practice guidelines for blood component therapy. Anesthesiology. 1996;84:732-47.

\section{Reimplantation of a left internal thoracic artery during repeat coronary artery revascularization: Early and midterm results}

Miralem Pasic, MD, PhD, Peter Müller, MD, Peter Bergs, MD, llirijana Karabdic, MD, Wolfgang Ruisz, MD, Michael Hofmann, MD, and Roland Hetzer, MD, PhD, Berlin, Germany

$\mathrm{W}$ hen used as an aorta-coronary bypass graft, the left internal thoracic artery (LITA) might remain open, despite significant restriction of flow through the graft. Potentially, a patent but nonfunctioning LITA might be reharvested and reused for repeat coronary artery bypass surgery (so-called LITA recycling). We

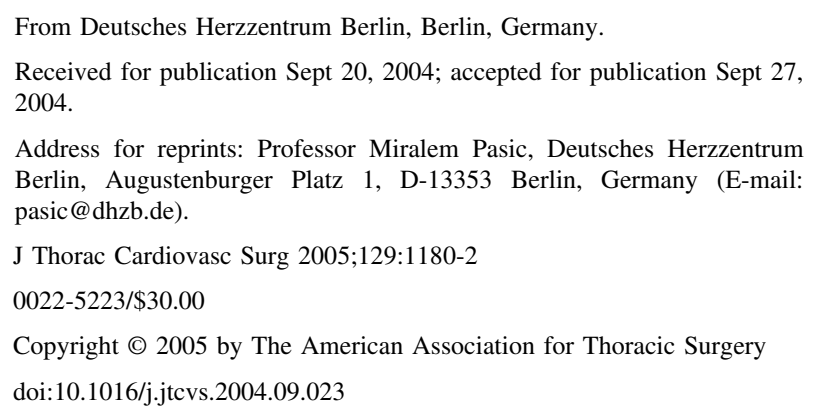

report on our experience with successful reimplantation of the LITA during redo bypass surgery in 12 patients.

\section{Patients and Methods}

Between 1997 and 2003, the LITA was reharvested and reinserted in 12 patients undergoing repeat coronary artery bypass grafting. There were 3 women and 9 men. The mean \pm SD age of the patients was $64 \pm 7$ years (range, 53-74 years). Written informed consent was obtained from all patients. The patients' mean left ventricular ejection fraction was 38\% $\pm 16 \%$ (range, 25\%-60\%). The patent but nonfunctioning LITA was reused only if preoperative coronary angiography showed that the diameter of the LITA lumen was normal or almost normal. This was assessed by the respective surgeon according to his experience, and he considered it to be feasible.

The causes of LITA dysfunction were anastomotic problems in 7 patients and progression of atherosclerotic disease of the native vessel distal to the previous anastomosis in 5 patients. Stenosis of the anastomosis between the LITA and the left anterior descending coronary artery (LAD; Figure 1) was found in 5 patients and 